\title{
Mezoterapi ve Klinik Uygulamalar
}

\author{
Mesotherapy and Clinic Application
}

\author{
Ahmet Atalık \\ Yazışma Adresi / Correspondence: \\ Dr. Ahmet Atalık \\ Emaar Square Heights E Blok 2301 Ünalan Mah. Üsküdar, İstanbul TÜRKiYE \\ E-mail: : ahmetatalik@yahoo.com \\ Orcid \\ Ahmet Atalık: https://orcid.org/0000-0003-3183-5011
}

Geliş Tarihi / Received : 20-08-2019

Kabul Tarihi / Accepted : 24-08-2019

Yayın Tarihi / Online Published: 30-09-2019

Atalık A., Mezoterapi ve Klinik Uygulamalar , J Biotechnol and Strategic Health Res. 2019;3(Özel Sayı):115-118 DOI: bshr.607437

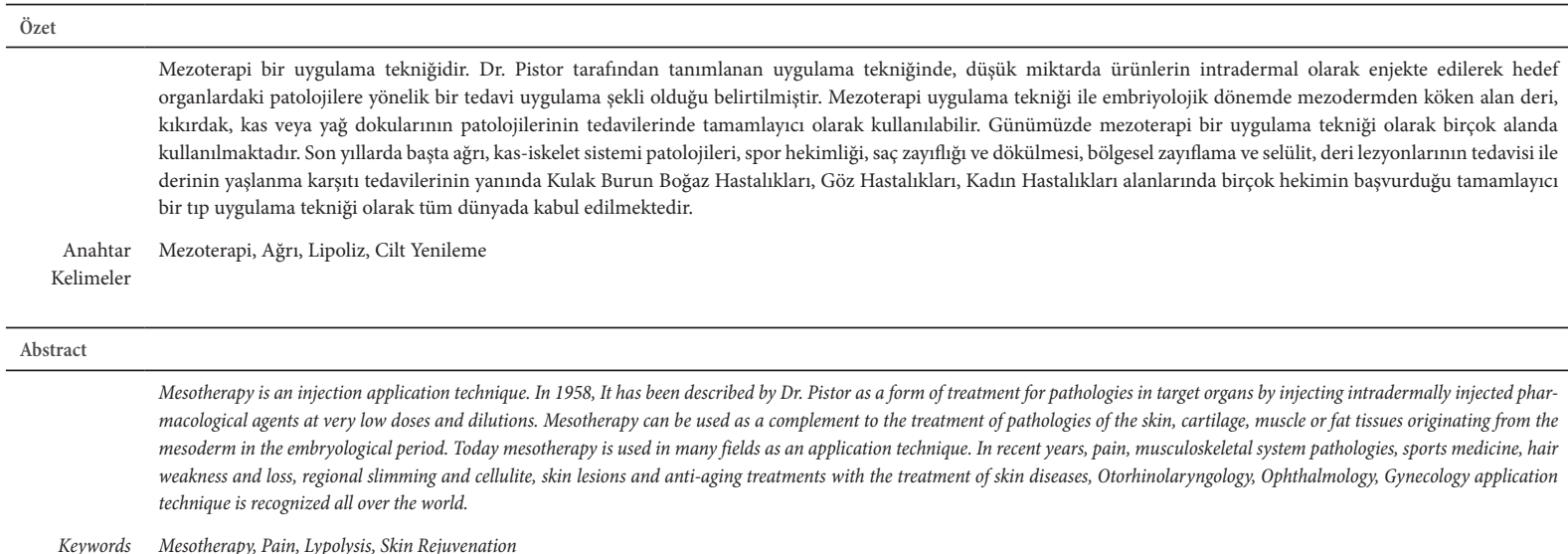




\section{Giriş}

Dr. Pistor, 1958'de La Presse Medicale'de bulgularını yayınladığı "Prokaine yerel ve patolojinin insanda yaşadığı bir provayı ortaya çıkar" başlıklı bir makalesinde (İnsan Patolojisinde Yerel Olarak Uygulanan Prokainin Yeni Özelliklerinin Kısa Açıklaması) mezoterapi terimini kulland ${ }^{1}$. Mezoterapi uygulama tekniği ile embriyolojik dönemde mezodermden köken alan deri, kıkırdak, kas veya yağ dokularının patolojilerinin tedavilerinde tamamlayıcı olarak kullanılabilir². Mezoterapi uzun yıllardır başta Avrupa ülkeleri olmak üzere deri lezyonları ve yaşlanma karşıtı çalışmalarda, fizik tedavi, ortopedi ve spor hekimliği gibi birçok farklı alanda tıbbi çalışmaların bir parçası olarak uygulanmaktadır.

Ülkemizde 2014 yılına kadar çok fazla aktif uygulayıcısı ve sertifikalı hekimi olmayan mezoterapi 04.02.2014 tarihli ve 28903 sayılı Resmî Gazete 'de yayımlanan' Sağlık Bakanlığı Sertifikalı Eğitim Yönetmeliği”’3 ve 27.10,2014 tarihli ve 29158 sayılı Resmî Gazete 'de yayımlanan "Geleneksel ve Tamamlayıcı Tip Uygulamaları Yönetmeliği” ne dayanarak Sağlık Bakanlığı tarafından yetki verilen üniversite ve araştırma hastaneleri bünyesinde kurulan eğitim merkezlerinde tıp doktoru ve diş hekimlerine yönelik sertifikalı eğitim programı olmuştur. Mezoterapi Derneği, Sağlık Bakanlığı onaylı mezoterapi uygulama sertifikası almaya hak kazanan tıp doktorlarının eğitim sonrası bilgi, uygulama pratiği ve tecrübelerini artıracak eğitimlerin yanında haklarının korunması amacıyla da ülkemizde faaliyet göstermektedir.

Mezoterapi uygulama tekniğinde amaç intradermal enjeksiyonlar ile $4 \mathrm{~mm}$ derinliğe kadar ürünlerin bir havuz olacak şekilde bırakılmasıdır ${ }^{5}$. Kullanılan ürünler, tedavi endikasyonları çerçevesinde gerekli ise seyreltilerek patolojinin olduğu bölgeye çoklu enjeksiyonların belirli aralıklarla tekrarlanması planlanır. Uygulama sıklığı bu kriterlere göre saptanır. Genellikle ağrı mezoterapisinde üç seansın sonunda sonuçlar değerlendirilerek tedaviye devam, tamam veya ürün değişikliği planlanır 6 .
Mezoterapi tekniği ile hastalara verilen tedavi dozu ve ilaca bağlı yan etkiler azaltılmış, etkinlik artırılmıştır5. Mezoterapide kullanılan ürünler suda çözünen ve birlikte uygulandığında çökme göstermeyen ilaç veya kokteylleridir². Mezoterapi seanslar şeklinde uygulanır. Bu seanslar akut durumlarda haftada iki kez kronik durumlarda haftada 1 kez olarak başlanabilir. Hastanın ağrı durumuna göre seans sayısı düzenlenir.

Kullanılan ana ürünlere baktığımızda analjezik ve sempatolitik etkileriyle lidokain, prokain, ksilokain; analjezik ve antienflamatuvar etkileri için piroksikam; dolaşım düzenleyici olarak pentoksifilin, fonzilan; deri yenilenmesi ve fibroblastların uyarılması için hyaluronik asit, vitaminler, PZP (PRP), mineraller, organik silisyum, saç zayıflığı ve dökülmesi için, dutasterid, biotin veya minoksidil; bölgesel zayıflama veya adipolitik etki için aminofilin, kafein, deoksikolat, fosfatidilkolin; antioksidan destek için glutatyon ve A,C,E vitaminleri içeren karışımlar tercih edilmektedir.

Mezoterapi uygulamalarında 4, 6, 8, 13 mm'lik ince (27, 30,32 G) iğne uçları tercih edilir. Uygulama elle yapılabildiği gibi mezoterapi tabancaları vasıtasıyla da olabilir. Deri lezyonlarında tedavide roller ve mikro iğneleme enstrümanları da günümüzde standart ve homojen tedavi için tercih edilmektedir.

Mezoterapi etki mekanizmasının kesin ortaya konamaması nedeniyle tüm dünyada tamamlayıcı bir uygulama tekniği olarak kabul edilmektedir. İğnenin mekanik delme etkisine ve uygulanan ilacın kimyasal etkisine bağlı olarak lokal, bölgesel ve merkezi etkilerden söz edilmektedir ${ }^{1,5}$. Bu etkileri açıklamaya çalışan yedi farklı teori vardır.

Akut ve kronik ağrı tedavisi, bağ doku patolojileri, romatizmal hastalıklar, spor hekimliğinde mezoterapi tedavi için kullanılabilir ${ }^{1,6}$. İ̆gnenin deriyi delmesi ile ağrı kesme mekanizması (kapı kontrol) devreye girer bunun yanında verilen ilaç ve lokal anestezik kullanımı ile bu etki pekiş- 
tirilir. Ağrılı durumlardan en çok karşılaşılan durumlar diskopati, artroz gibi boyun, sırt ve bel ağrısına yol açan patolojiler, omuz ve diz gibi eklem zedelenmeleri, bursit, tendinit sinovit gibi yumuşak doku patolojileri, romatoid artrit, ankilozan spondilit gibi romatizmal hastalıklar ve karpal tünel sendromu ve siyatalji gibi sinir tuzaklanma patolojileridir ${ }^{2}$. Lokomotor sistem patolojilerinde akut durumlarda lokal anestezik, myorelaksan ve nonstreoid antiinflamatuar (NSAİI) maddeler karıştırılarak kullanılır, kronik durumlarda bu karışıma pentoksifilin türevleri gibi dolaşım düzenleyiciler eklenir².

Yaşlanma karşıtı çalışmalarda cilt gençleştirme, yenileme ve onarımına yönelik uygulamalar yapılır. Bu alanda Mezolift tekniği uzun ylllar önce Dr Pistor tarafindan bulundu ${ }^{1,5}$. Yüz, boyun ve dekolte bölgesine uygulanacak vitamin, mineral, peptid, aminoasit, hyaluronik asit ve kollajen sentezini destekleyecek mezoterapi ürünlerinden oluşan tüm enjeksiyonlar 2-2,5 mm derinliğe uygulanma$l_{1} \mathrm{~d}^{2}{ }^{2}$. Enjeksiyon başına enjekte edilen miktarlar maksimum 0,02-0,05 ml ile sinırlı ve iki enjeksiyon noktası arasindaki mesafe epidermiste 1-2 cm olmalıdır. Tek seansta kullanılacak olan ürün miktarı uygulama alanı ve cildin durumuna göre 2,5-5ml arasındadır.

Mezoterapi yöntemleri, kadınlardaki androjenik saç dökülmelerinde, erkeklerin androjenik saç dökülmesinin erken başlangıç devresinde, kadınlarda doğum sonrası saç dökülmelerinde, saçlı deri, sakal, kaşlar gibi bölgesel dökülmelerde önemli bir tedavi protokolü olarak kullanılmaktadır ${ }^{2}$. Mezoterapi, gerek uygulama şekli gerek sonuç olarak, geleneksel ilaçların oral, i.v , i.m gibi sistemik kullanımlarına göre daha etkilidir. Prokain, lidokain, biotin, bepanthen, trental, fonzylene, multivitaminler, vitamin A, oligoelementler, antiandrojenler, finasteride ürünlerinden hazırlanan kokteyller günümüzde sıkça tercih edilmektedir. Her seansta toplam 2,5-3 ml ürün kullanılabilir. İlk ay haftada bir, ikinci ay on beş günde bir ve sonrasında ayda bir olmak üzere tedavi planlanabilir.
2004 yılında Rotunda ve arkadaşları subkutan enjeksiyonlar için kullanılan lipolitik ürün kokteylinin (fosfatidilkolin ve sodyum deoksikolat) iki ana bileşenini enjekte ettikleri bir çalışma ile kokteylin aktif kısmının sodyum deoksikolat olduğu ve bir yağ hücre duvarının spesifik olmayan bir şekilde parçalanmasına neden olan bir deterjan görevi gördüğü sonucuna varmışlardır. ${ }^{78} 2005$ yılında Rose ve Morgan, fosfatidilkolin ve sodyum deoksikolat ile tedavi sonrası hastanın biyopsisinin patolojik incelemesini gösteren bir çalışma yayınladı. Histoloji, yağ dokusunda inflamasyon ve nekroz gösterdi ${ }^{9}$.

Göbek ve bel çevresi üst bölge yağlanmalarında lipolitik etkili ilaçlar ve mikro sirkülasyon arttırıcı ilaçlar kullanılırken kalça ve uyluk bölgesinde ödem ve fibrozis birlikte bulunmaktadır. Genellikle Gynoid yağlanma olarak adlandırılır. Selülitte hormonların neden olduğu kapiller venöz ve lenfatik sistem bozukluğu söz konusudur. Enjeksiyon derinliği yağlanma selülit derinliğine göre $13 \mathrm{~mm}$ ye kadar değişebilir. Her noktaya 5-8 cm aralıklarla yaklaşık 0.2$04 \mathrm{ml}$ ürün uygulanır. Özellikle selülit tedavisinde fibröz bantların eritilmesi için kullanılan proteolitik ürünler, Kolajenaz, Hyaluronidaz alerjik reksiyonlara neden olabildiğinden dikkatli kullanılmalıdır. Adipositlerden serbest yağ asitleri (SYA) ve trigliseritleri hücre dışına çıkaran ve adipolitik etken maddeler: Yohimbin alpha, Tratricol, Aminofilin, Euphyllin, Alcaxantina (alcacopha ve aminofilin), fosfatidil kolin, deoxycholate, L carnitin, Kafein, Koenzim A. Dolaşım Düzenleyiciler: Benzopyron(coumarin), Buflomedil, Melilot-rutine, Ginkgo bilabo, Pentoxyfyllin, Procain, Lidokain.

18 ile 75 yaşları arasında genel sağlık durumu iyi olan herkese mezoterapi uygulama tekniği ile tedavi yapılabilir. Hamileler, emziren anneler, kontrol altına laınmamış hipertiroidiler, kanama diyatez bozuklukları, genel durumu bozuk, ileri kalp ve kanser hastalarına uygulama yapılması önerilmemektedir. Uygulama bölgesinde aktif deri hastalığı veya enfeksiyon olması da tedavinin yapılmasına izin vermemektedir. Ayrıca bölgesel zayıflama uygulamaların- 
da böbrek ve karaciğer bozuklukları ile lenfatik ve dolaşım bozukluklarında önerilmemektedir.

\section{SONUÇ}

Mezoterapi günümüzde düşük doz ürün kullanımı ve yan etkilerinin azlığı nedeniyle ağrı tedavisinde ve spor hekimliğinde yaygın olarak kullanılmakta ve gelişmeye devam etmektedir. Yaşlanma karşıtı tedavilerde de derinin kaybettiği ve ihtiyacı olan ürünlerin yerine konma tedavisi olduğu için iyi ve doğal yaşlanmayı sağlamakta, her gün artan bir taleple rağbet edilmektedir. Mezoterapi ile koruyucu ve önleyici yaşlanma karşıtı uygulamaların gelecekteki olumlu etkileri ve düşük maliyetleri de ilginin artmasına neden olmaktadır. Özellikle Batı Avrupa'da, yaşının iyisi olmak isteyen ve yaşlanmasını yönetmek isteyen bilinçli kişilerin öncelikli tercihleri artık mezoterapidir.

Yaşlanma karşıtı uygulamaların yanında saç dökülme ve zayıflığ rinde başarılı sonuçlar alınmaktadır. Yaygın kullanımının yanında mezoterapi'de kullanılan birçok ürünün etkinliği, dozu ve tedavi protokolü ile standartların yetersiz olması tedavi etkinliğinde değişkenlikler görülmesine yol açmaktadır. Mezoterapi alanında çalışan hekimlerin yapacağı klinik çalışmalar ve yayınlar ile ihtiyaç duyulan bilimsel kanıtların oluşturulması ile önemli katkılar sağlanacak ve yol gösterici olacaktır. 
Journal of BSHR 2019;3(Özel Sayı):115-118

ATALIK. Mezoterapi

\section{Kaynaklar}

1. Pistor M. What is mesotherapy? Chir Dent Fr. 1976; 46: 59-60.

2. İstanbul Medipol Universitesi Mezoterapi Ders Notları, 2017

3. Sağlık Bakanlı̆̆ı Sertifikalı Ĕ̆itim Yönetmeliği, 2014

4. Sağlık Bakanlığı Geleneksel ve Tamamlayıcı Tip Uygulamaları Yönetmeliği, 2014

5. Pistor M. Mèsothèrapie pratique. 1st ed. Paris: Masson; 1998

6. Le Coz J. MesotherapyéLipolysis, Estetic Medic Pre Ltd,Singapore 2008
7. Rotunda AM, Suzuki H, Moy RL, Kolodney MS. Detergent effects of sodium deoxycholate are a major feature of an injectable phosphatidyl choline formulation used for localized fat dissolution. Dermatol Surg. 2004;30:1001-8.

8. Rotunda AM, Kolodney MS. Mesotherapy and phosphatidylcholine injections: Historical clarification and review. Dermatol Surg 2006

9. Rose PT, Morgan M. Histological changes associated with mesotherapy for fat dissolution. 